\title{
Article \\ Radiative and Non-Radiative Decay Pathways in Carbon
Nanodots toward Bioimaging and Photodynamic Therapy
}

Yujin Kim ${ }^{1,+}{ }^{\circ}$, Yoonsang Park ${ }^{1,2,+}$, Seulgi Han ${ }^{3,+}$, Wonchan Park ${ }^{3}$, Mungu Kim ${ }^{3}$, Kyunghwan Kim $^{4}$, Jinmyoung Joo ${ }^{5}$, , Sei Kwang Hahn ${ }^{3, *}$ and Woosung Kwon ${ }^{1,2, *(\mathbb{D}}$

1 Department of Chemical and Biological Engineering, Sookmyung Women's University, Seoul 04310, Korea; eugene5980@sookmyung.ac.kr (Y.K.); ypark@keti.re.kr (Y.P.)

2 Institute of Advanced Materials and Systems, Sookmyung Women's University, Seoul 04310, Korea

3 Department of Materials Science and Engineering, Pohang University of Science and Technology (POSTECH), Pohang 37673, Korea; seulgihan@postech.ac.kr (S.H.); mlblucky@postech.ac.kr (W.P.); kimmungu@postech.ac.kr (M.K.)

4 Department of Chemistry, Ulsan National Institute of Science and Technology (UNIST), Ulsan 44919, Korea; starcato@unist.ac.kr

5 Department of Biomedical Engineering, Ulsan National Institute of Science and Technology (UNIST), Ulsan 44919, Korea; jjoo@unist.ac.kr

* Correspondence: skhanb@postech.ac.kr (S.K.H.); wkwon@sookmyung.ac.kr (W.K.); Tel.: +82-54-279-2159 (S.K.H.); +82-2-2077-7398 (W.K.); Fax: +82-54-279-2399 (S.K.H.); +82-2-2077-7278 (W.K.)

+ These authors contributed equally to this work.

Citation: Kim, Y.; Park, Y.; Han, S.; Park, W.; Kim, M.; Kim, K.; Joo, J.;

Hahn, S.K.; Kwon, W. Radiative and Non-Radiative Decay Pathways in Carbon Nanodots toward Bioimaging and Photodynamic Therapy. Nanomaterials 2022, 12, 70. https://doi.org/10.3390/ nano12010070

Academic Editors: Aharon Gedanken, Zeev Porat and Vijay Bhooshan Kumar

Received: 11 November 2021 Accepted: 27 December 2021 Published: 28 December 2021

Publisher's Note: MDPI stays neutral with regard to jurisdictional claims in published maps and institutional affiliations.

Copyright: (C) 2021 by the authors. Licensee MDPI, Basel, Switzerland. This article is an open access article distributed under the terms and conditions of the Creative Commons Attribution (CC BY) license (https:// creativecommons.org/licenses/by/ $4.0 /)$.

\begin{abstract}
The origin and classification of energy states, as well as the electronic transitions and energy transfers associated with them, have been recognized as critical factors for understanding the optical properties of carbon nanodots (CNDs). Herein, we report the synthesis of CNDs in an optimized process that allows low-temperature carbonization using ethanolamine as the major precursor and citric acid as an additive. The results obtained herein suggest that the energy states in our CNDs can be classified into four different types based on their chemical origin: carbogenic core states, surface defective states, molecular emissive states, and non-radiative trap states. Each energy state is associated with the occurrence of different types of emissions in the visible to near-infrared (NIR) range and the generation of reactive oxygen species (ROS). The potential pathways of radiative/non-radiative transitions in CNDs have been systematically studied using visible-to-NIR emission spectroscopy and fluorescence decay measurements. Furthermore, the bright photoluminescence and ROS generation of these CNDs render them suitable for in vitro imaging and photodynamic therapy applications. We believe that these new insights into the energy states of CNDs will result in significant improvements in other applications, such as photocatalysis and optoelectronics.
\end{abstract}

Keywords: carbon dot; near-infrared; reactive oxygen species; bioimaging; photodynamic therapy

\section{Introduction}

Over the past few decades, carbon nanodots (CNDs) have been recognized as luminescent materials with properties related to photostability, biocompatibility, and bioavailability. These properties enable CNDs to be used in the biomedical field for potential applications in bioimaging [1-5], biosensing [6-9], gene/drug delivery [10-13], and other nano-therapeutics $[14,15]$. Depending on the synthetic procedures and conditions, different core structures with various surface functional groups can be obtained for CNDs, endowing them with unique optical properties such as broadband and excitation-dependent photoluminescence (PL).

Radiative recombination or PL pathways in CNDs have been suggested in several studies: (i) carbogenic core states [16-18], (ii) surface defective states [19-21], and (iii) molecular emissive states [22-24]. The interactions between these PL pathways are strongly dependent on the chemical structure of CNDs; however, a comprehensive PL mechanism of these 
pathways remains unclear and controversial. One possible reason for this is that various preparation methods for CNDs lead to intrinsically different chemical structures, making any comparison between different CNDs almost impossible. Therefore, various experimental parameters that affect the optical properties of CNDs have been discovered, such as reaction temperature [25-27], heteroatom doping [28-30], and surface passivation [31-33]; however, further investigations are needed to evaluate the effects of these parameters.

Various types of CNDs and their chemical structures have been widely studied. Particularly, CNDs produced by the carbonization of organic acids and amines have been studied due to their ease of synthesis and high reaction yields. According to Song et al., molecular fluorophores with molecular emissive states are expected to form at low temperatures, whereas states with surface defects are predominantly formed at high temperatures [34]. Schneider et al. reported that the use of different amine precursors could change the PL intensity due to the formation of different molecular fluorophores [35]. The following areas of investigation emerge from these studies: (a) the reaction conditions required to form different types of chemical structures and energy states, (b) potential interactions occurring between the energy states, and (c) effect of these interactions on radiative and non-radiative transitions.

In this work, we report the synthesis of CNDs at relatively low temperatures $\left(<100{ }^{\circ} \mathrm{C}\right)$ and investigate the generation of different energy states by controlling the addition of ethanolamine (EA) and citric acid (CA). Results obtained herein suggest that CNDs have four different types of energy states: carbogenic core states, surface defective states, molecular emissive states, and non-radiative trap states. Different types of emissions associated with each of these energy states and the potential pathways of radiative/non-radiative transitions have been thoroughly studied using visible-to-near infrared (NIR) PL spectroscopy and fluorescence decay measurements. Finally, we have assessed the potential of CNDs for in vitro imaging and photodynamic therapy (PDT) of adenocarcinomic human alveolar basal epithelial (A549) cells.

\section{Experimental Section}

\subsection{Reagents}

Citric acid and ethanolamine were purchased from Sigma-Aldrich (St. Louis, MO, USA). All chemicals were used as received without further purification.

\subsection{Synthesis of $\mathrm{CNDs}$}

The synthetic procedure for the synthesis of CND1 is as follows: Ethanolamine $(2 \mathrm{~mL})$ was first vigorously stirred at $90^{\circ} \mathrm{C}$ in air for $24 \mathrm{~h}$. After the allotted time, the solution was allowed to cool to room temperature. The black sticky liquid was dissolved in water and dialyzed against water for at least 3 days using Spectra/Por Biotech Cellulose Ester dialysis tubes (Spectrum Chemical Mfg. Corp., Gardena, CA, USA) (100-500 Da). After the water was removed from the solution by lyophilization, the resulting powder was stored in a freezer for further use. The same procedure was followed for the synthesis of CND2, CND3, and CND4. The amounts of aqueous citric acid solution $\left(1 \mathrm{~g} \cdot \mathrm{mL}^{-1}\right)$ added to ethanolamine $(2 \mathrm{~mL}$ ) for CND2, CND3, and CND4, were $200 \mu \mathrm{L}, 510 \mu \mathrm{L}$, and $2000 \mu \mathrm{L}$, respectively. The reaction yield of CNDs was ca. $100 \mathrm{mg}$.

\subsection{Material Analysis}

Transmission electron microscopy (TEM) was performed using a Jeol JEM-2200FS instrument (Jeol Ltd., Tokyo, Japan) equipped with a Cs corrector. High-performance liquid chromatography (HPLC) was performed using the following Shimazdu equipment (Shimadzu Corp., Kyoto, Japan): SIL-20A autosampler, LC-20AD pump, SPD-20A dual $\lambda$ absorbance detector, and Shim-pack GIS-ODS $5 \mu \mathrm{m}$ column. A 1:1 vol\% mixture of water and methanol (flow rate: $0.8 \mathrm{~mL} \cdot \mathrm{min}^{-1}$ ) was used as the mobile phase. The injection volume was $25 \mu \mathrm{L}$. The CNDs were detected at wavelengths of $350 \mathrm{~nm}$. Dynamic light 
scattering (DLS) and zeta potential measurements were performed using a Horiba SZ-100 particle-size analyzer (Horiba Ltd., Kyoto, Japan).

\subsection{Chemical Analysis}

X-ray photoelectron spectroscopy (XPS) was performed using an Escalab 250 spectrometer with an Al X-ray source (1486.6 eV) (VG Scientific Corp., Beverly, MA, USA). Fourier-transform infrared (FT-IR) spectroscopy was performed using a Nicolet iS50 FTIR spectrometer (Thermo Scientific Corp., Madison, WI, USA). Raman spectroscopy was performed using a XperRam S spectrometer with $532 \mathrm{~nm}$ laser excitation (Alvatek Ltd., Tetbury, Glos, UK).

\subsection{Optical Analysis}

For spectroscopic measurements, $10 \mathrm{~mm} \times 10 \mathrm{~mm}$ QS-grade quartz cuvettes (Hellma Analytics 111-QS) were used. UV-vis absorption spectra were recorded on a Scinco S-3100 spectrophotometer (Scinco Co. Ltd., Seoul, Korea). The PL spectra were recorded using a Jasco FP-8500 fluorometer (Jasco Inc., Tokyo, Japan). The absolute quantum yields were recorded on a Jasco FP-8500 fluorometer equipped with a $100 \mathrm{~mm}$ integrating sphere (ILF835) and calculated using Jasco Spectra Manager II Version 2 software (Jasco Inc., Tokyo, Japan). NIR PL spectroscopy was performed using a HORIBA PTI QM-500 spectrometer (Horiba Ltd., Kyoto, Japan) with a conventional diode laser as the light source $(660 \mathrm{~nm}$, $1 \mathrm{~W}$ ). Time-correlated single photon counting (TCSPC) measurements were performed using HORIBA Fluorolog-3 (Horiba Ltd., Kyoto, Japan); the emitted photon signal was spectrally dispersed by a monochromator and then collected using a fast photon multiplier tube detector.

\subsection{ROS Measurement}

Singlet oxygen sensor green (Thermo Fisher Scientific, Waltham, MA, USA) was used for the detection of singlet oxygen formation. The singlet oxygen sensor green was dissolved in $33 \mu \mathrm{L}$ of methanol in order to form a solution of a concentration of $5 \mathrm{mM}$. $4 \mu \mathrm{L}$ of the stock solution was added in $10 \mathrm{~mL} \mathrm{pH} 7$ buffer solution (Daejung Chemicals \& Metals Co. Ltd., Siheung, Gyeonggi, Korea). The CNDs were dispersed in $2 \mathrm{~mL}$ of the solution at concentration of $0.1 \mathrm{mg} \cdot \mathrm{mL}^{-1}$ in a quartz cuvette. After exposure to a UV lamp $(254 \mathrm{~nm}, 8 \mathrm{~W})$ for $2 \mathrm{~h}$, the fluorescence was determined and excitation wavelength of $504 \mathrm{~nm}$ and emission wavelength of 515 600 nm.

\subsection{Cell Viability Test}

The cytotoxicity of the CNDs in FL83B and A549 cells were evaluated using the cell counting kit-8 $($ CCK- 8$)$ assay. The cells $(1 \times 105$ cells $/ \mathrm{mL})$ were suspended in high-glucose Dulbecco's Modified Eagle Medium (DMEM) and supplemented with $1 \mathrm{wt} \%$ antibioticantimycotic solution and $10 \mathrm{vol} \%$ FBS. Subsequently, the cells were seeded in each of the 96 wells of the cell culture plates $(100 \mu \mathrm{L} /$ plate $)$ for $1 \mathrm{~d}$. The CNDs were dispersed in a serum-free medium (SFM) at concentrations of $0.125,0.25,0.5$, and $1 \mathrm{mg} \cdot \mathrm{mL}^{-1}$, and were added to each well. The cell culture plates were incubated at $37^{\circ} \mathrm{C}$ in a humidified $5 \%$ $\mathrm{CO}_{2}$ incubator for $1 \mathrm{~d}$. Subsequently, the cells were washed with fresh phosphate-buffered saline (PBS) twice and treated with 10\% CCK-8 assay solution. After an incubation period of $2 \mathrm{~h}$, the optical density of each well was measured at $450 \mathrm{~nm}$ using a microplate reader (Molecular Devices, Sunnyvale, CA, USA). The experiment was repeated four times.

\subsection{In Vitro Confocal Microscopy Imaging}

Cell imaging was performed using confocal microscopy on FL83B and A549 cells. FL83B and A549 cells were prepared at a concentration of $1 \times 10^{5}$ cells $/ \mathrm{mL}$ in high-glucose DMEM complete medium and seeded $(200 \mu \mathrm{L})$ in each chamber of the 8-chamber confocal slides for $24 \mathrm{~h}$. The medium was replaced with $200 \mu \mathrm{L}$ fresh SFM containing $1 \mathrm{mg} \cdot \mathrm{mL}^{-1}$ of $\mathrm{CNDs}$ and incubated at $37^{\circ} \mathrm{C}$ in a humidified $5 \% \mathrm{CO}_{2}$ incubator for $1 \mathrm{~d}$. Subsequently, 
the cells were washed with PBS twice and fixed with a $4 \%$ formaldehyde solution. The confocal slides were suspended with VECTASHIELD antifade mounting medium (H-1000) and fixed with cover slides. Cellular imaging with CNDs was excited with a diode-pumped solid-state (DPSS) laser at $405 \mathrm{~nm}$, and the emissions from the CNDs were detected at $420-500 \mathrm{~nm}$.

\subsection{In Vitro PDT Test}

The photodynamic therapy (PDT) efficacy of the CNDs was evaluated using A549 cells. Cell culture in the 96-well plate was carried out under the same conditions used for the cell viability test. After $1 \mathrm{~d}$ of cell culture time, the CNDs were added to each well at concentrations of $0.1,0.5$, and $1 \mathrm{mg} \cdot \mathrm{mL}^{-1}$, and the cell culture plate was incubated at $37^{\circ} \mathrm{C}$ in a humidified $5 \% \mathrm{CO}_{2}$ incubator for $1 \mathrm{~d}$. Afterwards, a $473 \mathrm{~nm}$ laser of $15 \mathrm{~mW} \cdot \mathrm{cm}^{-2}$ intensity was irradiated for $10 \mathrm{~min}$. The cells were subsequently incubated at $37^{\circ} \mathrm{C}$ for an additional $24 \mathrm{~h}$. After replacing the cell medium solution with $100 \mu \mathrm{L}$ of SFM, the CCK-8 assay solution was added to make $10 \%$ of the total concentration. After $2 \mathrm{~h}$ of incubation, the optical densities of each well were measured at $450 \mathrm{~nm}$ using a microplate reader.

\section{Results and Discussion}

The CNDs were synthesized via the oxidative carbonization of EA with a controlled amount of CA under ambient conditions. Generally, CA is used as the major precursor to form carbogenic cores and relatively a small amount of amine is needed to improve the colloidal stability and optical properties of CNDs [17,24,36,37]. Conversely, we have found that using EA as the major precursor ( $>70 \mathrm{~mol} \%$ ) and CA as an additive $(<30 \mathrm{~mol} \%)$ results in partially graphitic or polycrystalline CNDs at a low reaction temperature of $90^{\circ} \mathrm{C}$ (Figure 1a). The as-synthesized CNDs with different molar percentages of EA $(100,95,92$, and $70 \mathrm{~mol} \%)$ and $\mathrm{CA}(0,5,8$, and $30 \mathrm{~mol} \%)$ were labeled as CND1, CND2, CND3, and CND4, respectively.

TEM was performed to reveal the morphology and particle size of the CNDs. Figure $1 \mathrm{~b}-\mathrm{e}$ and Figure S1 shows TEM images of the CNDs with sizes ranging from 10-15 nm. As shown in Figure S2, regardless of the molar percentages of EA and CA, the size of the CNDs remains similar. The average size of the CNDs is approximately $9.91 \pm 2.24,10.25 \pm 1.84$, $10.37 \pm 1.98$, and $9.96 \pm 1.52 \mathrm{~nm}$ in order. The size distribution and dispersity were further examined by HPLC and DLS. HPLC analysis shows that the retention time remains constant for all CNDs (Figure S3). DLS measurements show a nearly monodispersed size distribution around $15 \mathrm{~nm}$ (Figure S4), which confirms the high dispersity of the CNDs. Furthermore, the CNDs have highly negative zeta potentials $(<-30 \mathrm{mV})$, which ensures the colloidal stability in water (Figure S5). The high-resolution TEM images show that the CNDs possess polycrystalline $\mathrm{sp}^{2}$ carbon clusters with the size ranging from 1-2 $\mathrm{nm}$ embedded in amorphous $\mathrm{sp}^{3}$ carbon matrices (Figure 1f,g) [38,39]. This amorphous nature of the CNDs was further confirmed by Raman spectroscopy (Figure S6).

FT-IR spectroscopy analyses were performed to investigate the surface chemistry of the CNDs. As shown in Figure 2, all the CNDs exhibited C-O stretching $\left(1055 \mathrm{~cm}^{-1}\right)$, aromatic $C=C$ stretching $\left(1350-1450 \mathrm{~cm}^{-1}\right.$ and $\left.1640 \mathrm{~cm}^{-1}\right), C-H$ stretching $\left(2850-2950 \mathrm{~cm}^{-1}\right)$, and $\mathrm{O}-\mathrm{H}$ stretching $\left(3200-3400 \mathrm{~cm}^{-1}\right)$ vibrational peaks, indicating the formation of polyaromatic structures and hydroxyl moieties in the CNDs. Additionally, a $\mathrm{C}=\mathrm{O}$ stretching vibrational peak $\left(1693 \mathrm{~cm}^{-1}\right)$ was observed for CND2-CND4 with the intensity increasing toward the direction of increase in $\mathrm{CA} \mathrm{mol} \%$. This indicates that a significant amount of carbonyl functional groups, mainly carboxylic acids, were formed on the surface of the CNDs after the addition of CA. With increase in the CA mol\% (CND3 and CND4), a new $C=C$ stretching vibrational peak $\left(1609 \mathrm{~cm}^{-1}\right)$ evolved while the original peak $\left(1640 \mathrm{~cm}^{-1}\right)$ remained preserved, indicating that the surface of the CNDs was modified to a large extent. 
EA

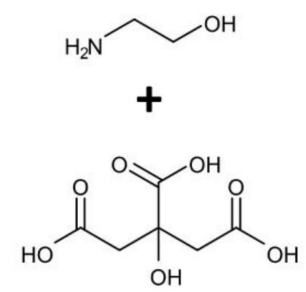

EA

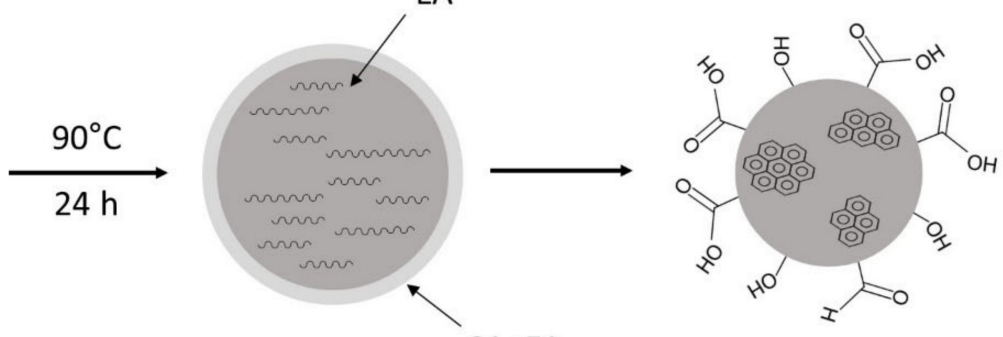

$\mathrm{CA}+\mathrm{EA}$ b

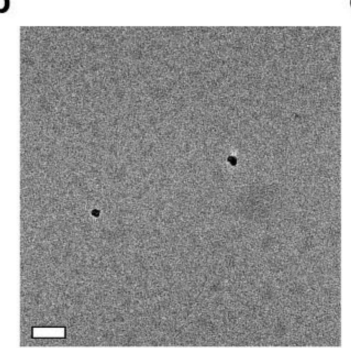

f

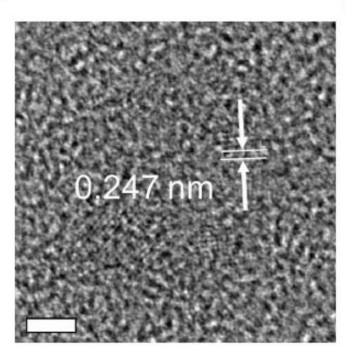

C

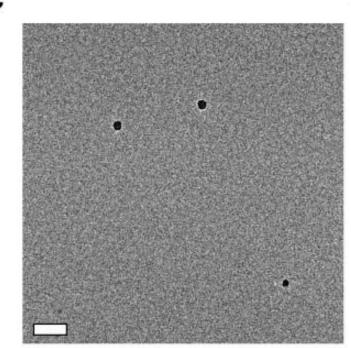

d

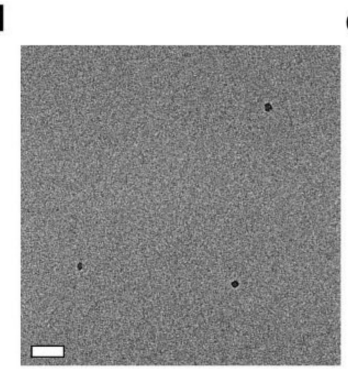

e

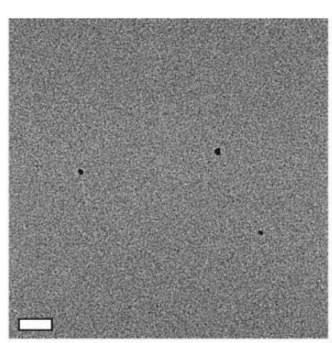

g

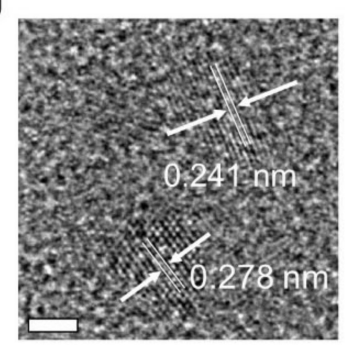

h

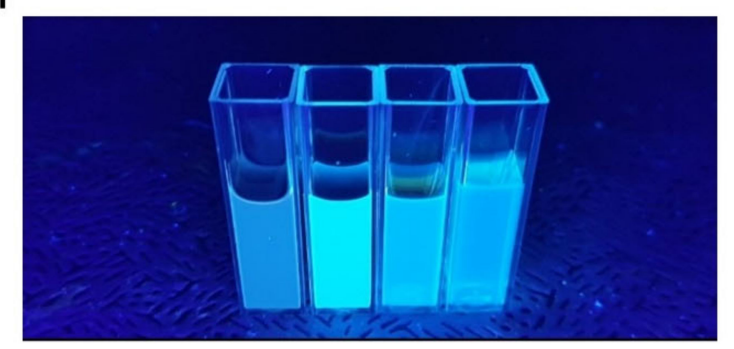

Figure 1. (a) Schematic illustration of the synthesis of CNDs. TEM images of (b) CND1, (c) CND2, (d) CND3, and (e) CND4. The scale bars represent $50 \mathrm{~nm}$. (f,g) High-resolution TEM images of CDs. The scale bars represent $2 \mathrm{~nm}$. (h) CND1-CND4 (left to right) under a $365 \mathrm{~nm}$ UV lamp.

The C1s XPS data further showed that the $\mathrm{C}=\mathrm{O}$ and $\mathrm{C}-\mathrm{O}$ signals were significantly enhanced with increasing CA mol\% (Figure S7). On the other hand, elemental analysis showed that the atomic $(\mathrm{C}, \mathrm{O}$, and $\mathrm{N})$ compositions of the $\mathrm{CNDs}$ remained at a similar level regardless of the CA mol\% (Table S1). Therefore, at low temperatures, the addition of CA results exclusively in the incorporation of carbonyl functional groups on the surface of the CNDs, rather than the formation of fully carbonized carbogenic structures with a high carbon content. The carbonyl functional groups are known to play a critical role in the occurrence of $\mathrm{PL}$, and are hereafter referred to as CA-derived fluorescent moieties (CAFMs).

The formation mechanism of our CDs is not fully understood at this stage but may involve thermal oxidation of EA, likely to yield a variety of degradation compounds such as acetamides, oxamides, formates, oxalates, glycines, imidazoles, etc. [40]. These compounds are composed of carbonyls and dienes that are considered to be important for the formation of polyaromatic hydrocarbons. According to Chen et al., EA was critical for the formation of both amorphous (the mixture of $\mathrm{sp}^{2}$ and $\mathrm{sp}^{3}$ ) and graphite-like $\left(\mathrm{sp}^{2}\right)$ carbons, which was confirmed by Raman spectroscopy [41]. This indicates that, in our case, the degradation compounds of EA may be decomposed and then reconstructed to form $\mathrm{sp}^{2}$ carbons of a conjugated $\pi$ electron system, which is responsible for the (partially) graphitic structure and related optical properties of the CDs.

To investigate the optical properties of the CNDs, we conducted UV-visible absorption and PL spectroscopy measurements. As shown in Figure S11, the absorption spectrum of CND1 shows a broad absorption band (250 to $550 \mathrm{~nm}$ ), arising from noncollinear $\pi$-plasmon transitions in the polyaromatic structures of the CNDs [42]. Another absorption 
band at $\sim 400 \mathrm{~nm}$ could be assigned to the $\mathrm{n}-\pi^{*}$ transition in the molecular energy state of CAFMs [15-17]. As soon as CA was added (CND2), a new absorption peak was observed at $\sim 340 \mathrm{~nm}$, indicating that CAFMs would provide certain intraband energy states. With a further increase in the CA mol\% (CND3 and CND4), the absorption peak at $340 \mathrm{~nm}$ enhanced, which confirmed that these intraband energy states were strongly related to CA and CAFMs.

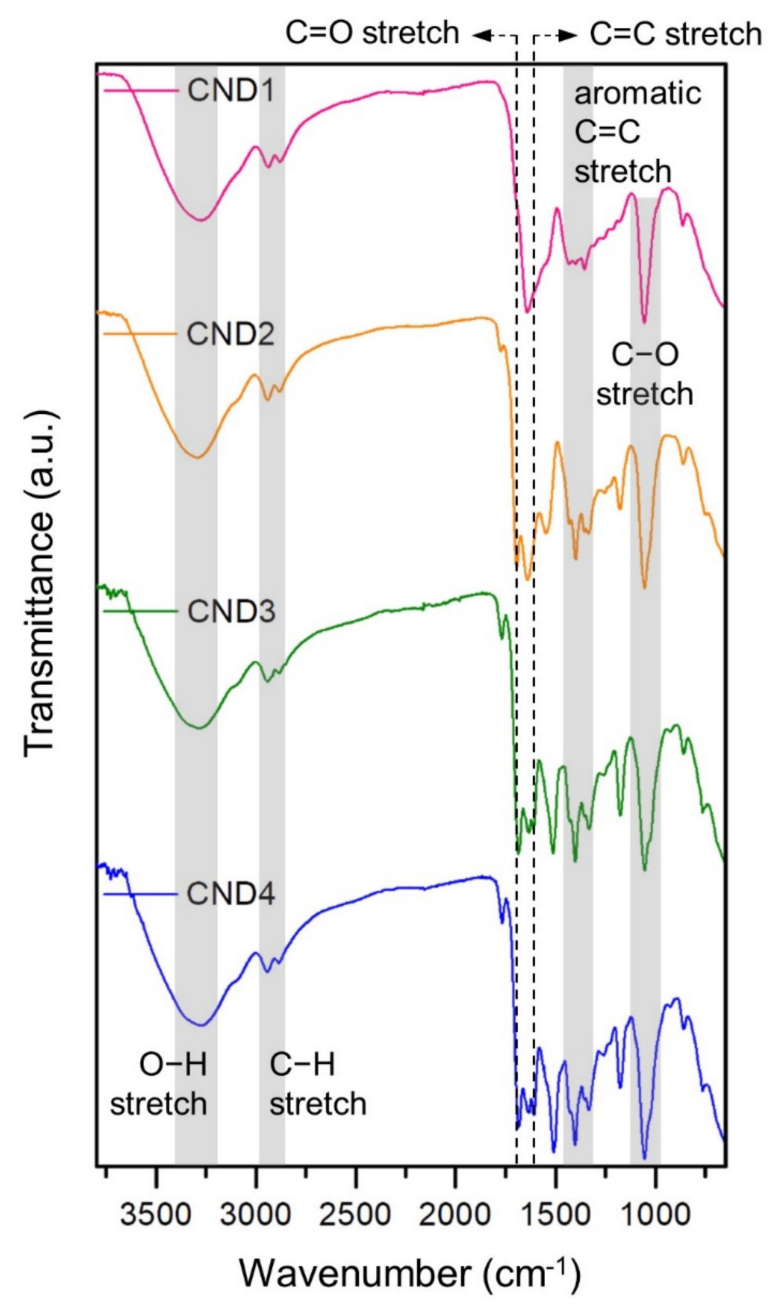

Figure 2. FT-IR spectra of the CNDs. The $\mathrm{C}=\mathrm{O}\left(1693 \mathrm{~cm}^{-1}\right)$ and $\mathrm{C}=\mathrm{C}\left(1640 \mathrm{~cm}^{-1}\right)$ stretch peaks are indicated by the dotted vertical lines.

The PL emission contour maps in Figure 3a-d exhibit a broad emission peak centered at $\sim 450 \mathrm{~nm}$ for all the CNDs. Although the peak emission wavelengths of the CNDs were almost the same, the detailed features of the emission spectra varied significantly with the CA mol\%. As shown in Figure 3e, the emission spectra of CND1 change significantly with respect to the excitation wavelengths. This excitation dependency is frequently observed in common CNDs and is explained by the presence of various surface emissive (or defective) states [43-45]. In this case, the excitation dependency gradually vanished with the addition of CA. CND4 exhibited completely excitation-independent emissions with a relatively narrow bandwidth. These are generally considered as the characteristics of molecular fluorophores, which indicates that CAFMs were formed predominantly when higher CA $\mathrm{mol} \%$ was used to create molecular emissive states (Figure $3 \mathrm{f}-\mathrm{h}$ ). The absolute quantum yields of the CNDs were ca. 5 15\% under the $365 \mathrm{~nm}$ excitation (Table S2). Our CNDs also exhibited excellent photostability against ambiance and/or UV (365 nm) irradiation; the PL intensities were mostly maintained after $10 \mathrm{~h}$ (Figure S12). 
a

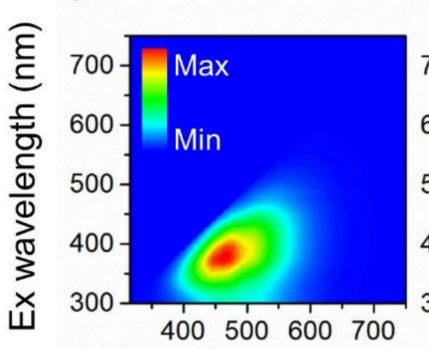

e
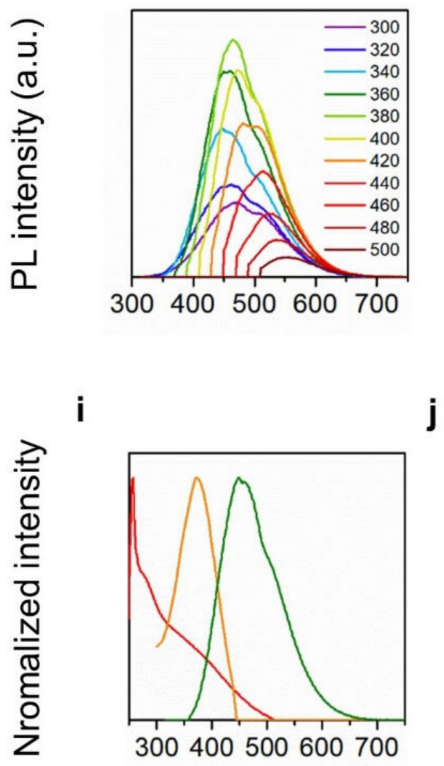

surface

m

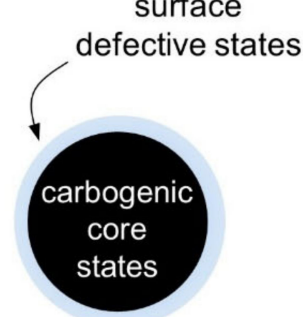

f b

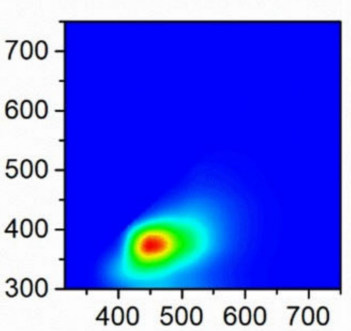

Em wavelength $(\mathrm{nm})$
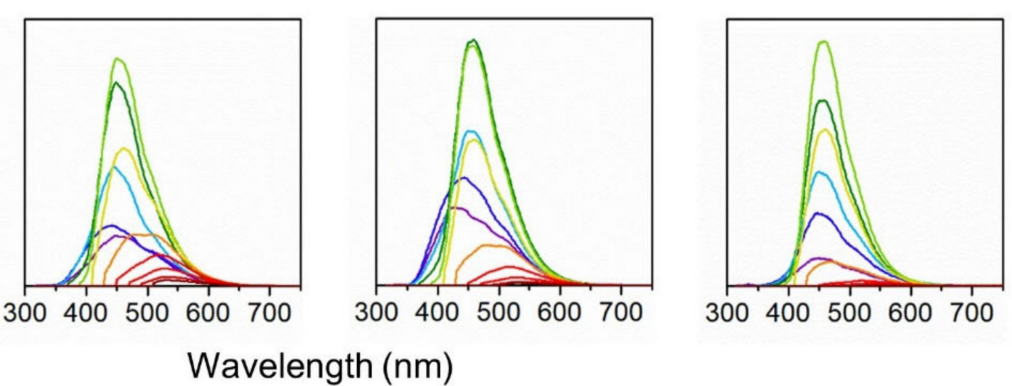

I

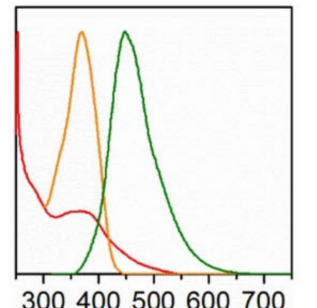

k
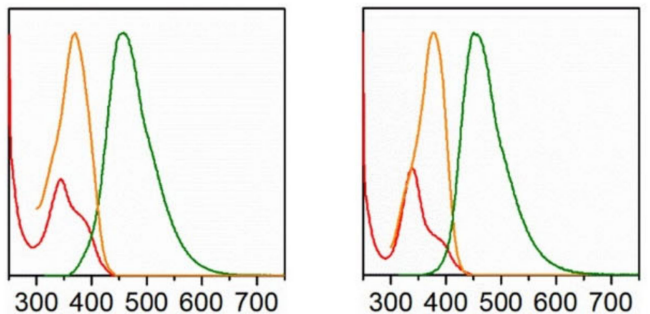

Wavelength $(\mathrm{nm})$

molecular emissive states
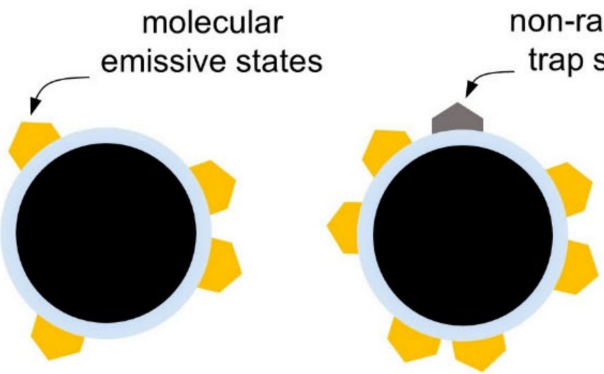

on-radiative

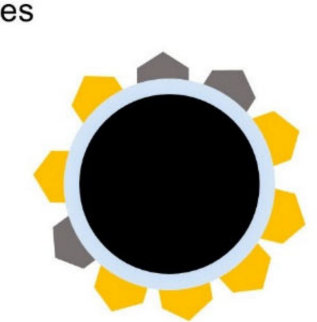

citric acid concentration

Figure 3. PL emission maps and spectra for excitation wavelengths of 300-600 $\mathrm{nm}$. Emission maps: (a) CND1, (b) CND2, (c) CND3, and (d) CND4. Emission spectra: (e) CND1, (f) CND2, (g) CND3, and (h) CND4. Absorption (red), excitation (orange), and emission (green) spectra: (i) CND1, (j) CND2, (k) CND3, and (1) CND4. (m) Schematic illustration of the change in chemical structure with increase in the concentration of citric acid.

Considering that the addition of CA mostly changed the surface structure of the CNDs, CAFMs are likely to be located on the surface of the CNDs. According to Song et al., the condensation of CA and ethylenediamine (EDA) resulted in blue-luminescent molecular fluorophores called IPCA [34]. Since EA is chemically similar to EDA, we suggest that CAFMs in CND2-CND4 play a similar role to IPCA. For instance, the strong carbonyl 
peaks of CAFMs previously observed in FT-IR and XPS were also found in IPCA due to carboxylic acid groups. Therefore, we conclude that CAFMs, being chemically similar to IPCAs, were formed on the surface of the CNDs, creating well-defined, molecular emissive states associated with the excitation-independent and narrow-bandwidth PL. As the molar percentage of CA increased, CAFMs and their molecular emissive states became dominant over the other PL origins. Consequently, the PL pathways in the CNDs converged to the molecular emissive states.

Interestingly, however, the PL intensity was not proportional to the CA $\mathrm{mol} \%$ or the amount of CAFMs formed in the CNDs. As shown in Figure S13, CND2 exhibited the highest PL intensity, which decreased with increasing CA mol\%. This indicates that the addition of CA could lead to the formation of not only CAFMs but also other chemical moieties with incomplete molecular structures that contain dangling bonds and radicals. These chemically incomplete moieties can create non-radiative trap states because of their instability and high electron affinity. To determine the presence of these non-radiative trap states, we compared the absorption, PL excitation, and PL emission spectra in Figure 3i-1. For CND3 and CND4, two distinct absorption peaks at $340 \mathrm{~nm}$ and $390 \mathrm{~nm}$ were observed, while the PL excitation peak was present only at $390 \mathrm{~nm}$. This indicates that excitons generated by the 340-nm excitation decay through a non-radiative pathway, and the energy state associated with this excitation is a non-radiative trap state. Therefore, as the CA $\mathrm{mol} \%$ increases, undefined molecular structures and the associated non-radiative trap states are formed along with CAFMs (Figure $3 \mathrm{~m}$ ). Since the FT-IR data implied that the $\mathrm{C}=\mathrm{C}$ stretching peak $\left(1609 \mathrm{~cm}^{-1}\right)$ became more pronounced with increasing $\mathrm{CA} \mathrm{mol} \%$, we deduced that these $\mathrm{C}=\mathrm{C}$ bonds might play a central role in generating non-radiative trap states.

TCSPC measurements were conducted to further investigate the energy states of the CNDs. As shown in Figure 4a and Table 1, the TCSPC signals of the CNDs were fitted using a tri-exponential decay model. We found that the average fluorescence lifetime reached its highest value in CND2, and then decreased with increasing CA mol\%, following the trend of the PL intensity. The average amplitudes of the long-lifetime components of CND2-4 were significantly higher than those of CND1, indicating that the densities of the long-lifetime excited states were increased by the addition of CA. Because the addition of CA is strongly related to the formation of CAFMs, we conclude that these long-lifetime excited states are directly associated with molecular emissive states. In contrast, the average amplitude of the short-lifetime components of CND4 was much higher than that of the other CNDs, indicating that non-radiative trap states were created in CND4 due to the presence of excess CA.

For CNDs in general, NIR PL has been considered to have different origins from the visible PL [46]. Although the exact mechanism remains unclear, it has been recently reported that polyaromatic core structures may play a major role in the occurrence of NIR PL [47]. In Figure 4b, CND1 and CND2 exhibit distinct NIR PL at around $750 \mathrm{~nm}$, whereas CND3 and CND4 exhibit negligible NIR PL. This could be caused by an increase in the rate of charge transfer from the core states to the surface states. Since the density of molecular emissive states is higher in CND3 and CND4 than in CND1 and CND2, the photoexcited electrons would have a greater chance of being relaxed through molecular emissive states (visible emission) than through carbogenic core states (NIR emission). We present an energy diagram of the CNDs in Figure 4c. The carbogenic core states and the surface defective states, both created by the low-temperature carbonization of EA, were responsible for the occurrence of NIR PL and excitation-dependent visible PL, respectively. The molecular emissive states (associated with the excitation-independent and narrow-bandwidth PL) and the non-radiative trap states can be created by the addition of CA. The PL characteristics and associated surface chemistry of the CNDs (summarized in Table S3) are compared with other types of CNDs derived from CA and amine derivatives (Table 2). 
a

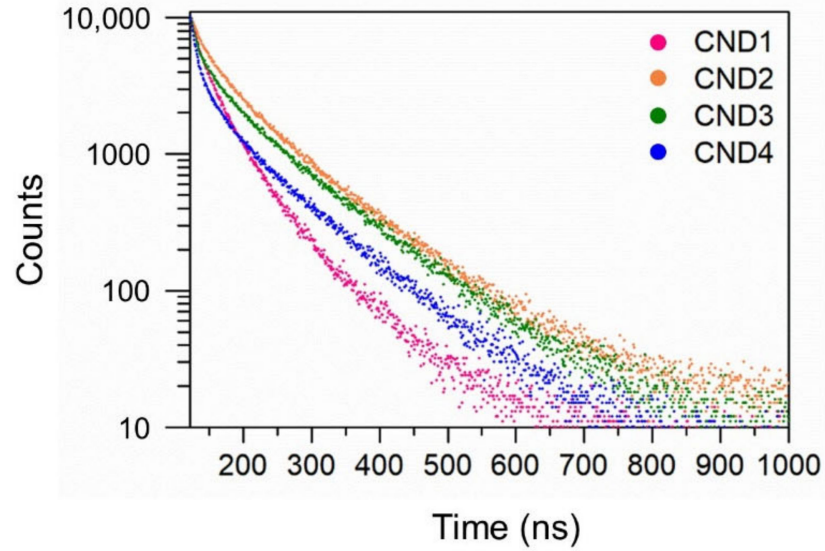

b

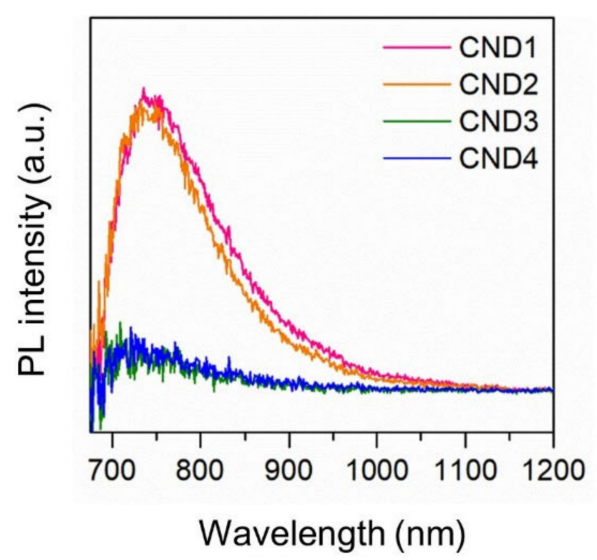

c

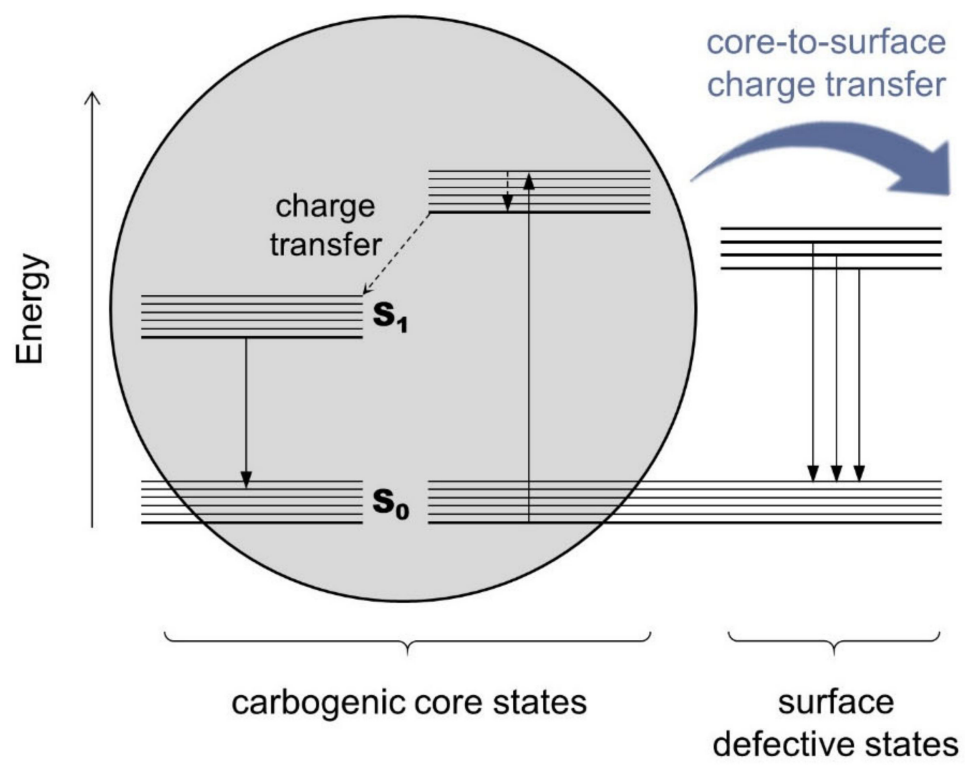

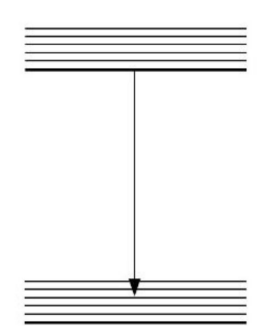

radiative recombination

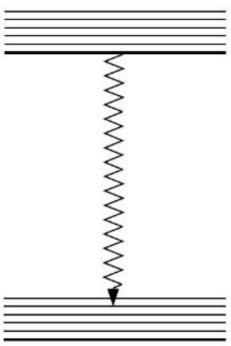

non-radiative decay

Figure 4. (a) TCSPC signals for CNDs recorded at detection wavelength of $450 \mathrm{~nm}$ with pump excitation wavelength of $374 \mathrm{~nm}$. (b) NIR PL emission spectra of the CNDs. (c) Schematic illustration of emission pathways and related surface structures of the CNDs.

Table 1. Fluorescence lifetimes of the CNDs.

\begin{tabular}{cccccccc}
\hline Sample & $\boldsymbol{\tau}_{\mathbf{1}}$ (ns) & $\boldsymbol{A}_{\mathbf{1}}$ & $\boldsymbol{\tau}_{\mathbf{2}}$ (ns) & $\boldsymbol{A}_{\mathbf{2}}$ & $\boldsymbol{\tau}_{\mathbf{3}}$ (ns) & $\boldsymbol{A}_{\mathbf{3}}$ & $\boldsymbol{\tau}_{\text {avg }}(\mathbf{n s})$ \\
\hline CND1 & 4.05 & 58.96 & 10.45 & 29.12 & 1.18 & 11.92 & 3.65 \\
CND2 & 5.03 & 30.50 & 12.66 & 63.44 & 1.39 & 6.07 & 6.47 \\
CND3 & 4.19 & 24.54 & 12.49 & 69.27 & 0.84 & 6.18 & 5.32 \\
CND4 & 3.91 & 24.96 & 11.71 & 60.67 & 0.88 & 14.37 & 3.58 \\
\hline
\end{tabular}

Finally, we investigated the behavior of photoexcited electrons in non-radiative trap states in CNDs (Figure 5a). As discussed earlier, these non-radiative trap states originate from incomplete chemical structures such as dangling bonds and radicals, which are capable of producing reactive oxygen species (ROS). To detect ROS generated by the CNDs, ROS assays were carried out using singlet oxygen sensor green (SOSG) as a ROS probe. In the presence of ROS, SOSG emits a green fluorescence similar to that of fluorescein, which exhibits PL at $525 \mathrm{~nm}$. After exposure to UV irradiation $(254 \mathrm{~nm})$ in the presence of SOSG for $2 \mathrm{~h}$, the PL intensities at $525 \mathrm{~nm}$ (in the aqueous solutions of the CNDs) were enhanced 
by 2-3 times compared to pure water (Figure S14). Interestingly, CND2-CND4 produced more ROS than CND1, which further confirmed our hypothesis that non-radiative trap states created by the addition of CA were responsible for ROS generation.

Table 2. Brief literature review of CNDs derived from the mixture of CA and amine derivatives.

\begin{tabular}{|c|c|c|c|c|c|c|}
\hline Precursors & $\begin{array}{l}\text { Reaction } \\
\text { Condition }\end{array}$ & Size (nm) & $\begin{array}{c}\text { PL Ex/Em } \\
\text { Wavelength }\end{array}$ & QY & Application & Ref. \\
\hline $\begin{array}{c}\text { Citric acid } \\
\text { Ethanolamine }\end{array}$ & $190^{\circ} \mathrm{C}, 2 \mathrm{~h}$ & $12.4 \pm 5.6$ & $\begin{array}{l}376 \mathrm{~nm} / \\
466 \mathrm{~nm}\end{array}$ & $11 \%$ & Subsurface tracer & [48] \\
\hline $\begin{array}{c}\text { Citric acid } \\
\text { Ethanolamine }\end{array}$ & $\begin{array}{c}230{ }^{\circ} \mathrm{C}, 30 \\
\mathrm{~m}\end{array}$ & 19 & $\begin{array}{l}375 \mathrm{~nm} / \\
455 \mathrm{~nm}\end{array}$ & $50 \%$ & - & [24] \\
\hline $\begin{array}{c}\text { Citric acid } \\
\text { Ethylenediamine }\end{array}$ & $140^{\circ} \mathrm{C}, 5 \mathrm{~h}$ & $\begin{array}{c}2 \sim 6 \\
\text { (carbon core) }\end{array}$ & $\begin{array}{l}361 \mathrm{~nm} / \\
442 \mathrm{~nm}\end{array}$ & $\begin{array}{c}70 \% \\
\text { (relative) }\end{array}$ & - & [34] \\
\hline $\begin{array}{c}\text { Citric acid } \\
\text { Ethylenediamine }\end{array}$ & $120^{\circ} \mathrm{C}, 15 \mathrm{~h}$ & $3.5 \pm 0.3$ & $\begin{array}{l}340 \mathrm{~nm} / \\
440 \mathrm{~nm}\end{array}$ & $\begin{array}{c}21.8 \% \\
\text { (relative) }\end{array}$ & - & [17] \\
\hline $\begin{array}{l}\text { Citric acid } \\
\text { Triethylamine }\end{array}$ & $160^{\circ} \mathrm{C}, 4 \mathrm{~h}$ & $1.7 \pm 0.21$ & $\begin{array}{l}350 \mathrm{~nm} / \\
437 \mathrm{~nm}\end{array}$ & $18.8 \%$ & $\mathrm{Hg}^{2+}$ detection & [49] \\
\hline $\begin{array}{c}\text { Citric acid } \\
\text { Ethanolamine }\end{array}$ & $90^{\circ} \mathrm{C}, 24 \mathrm{~h}$ & $10.25 \pm 1.84$ & $\begin{array}{l}360 \mathrm{~nm} / \\
450 \mathrm{~nm}\end{array}$ & $15.24 \%$ & Bioimaging and PDT & This work \\
\hline
\end{tabular}

a

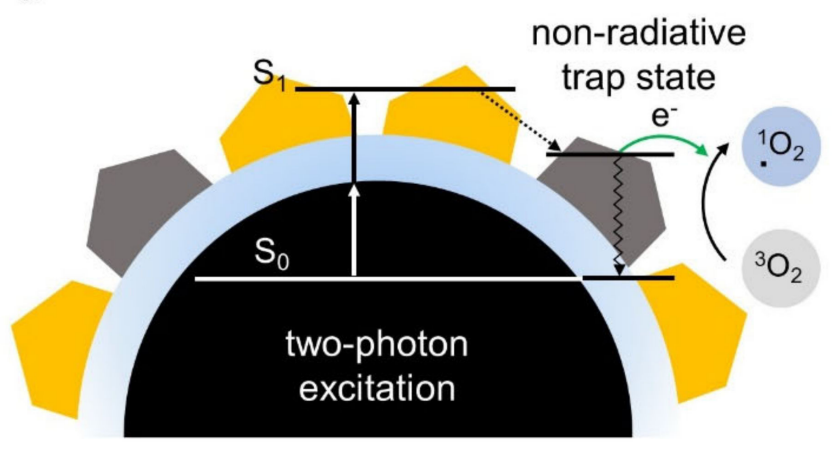

b

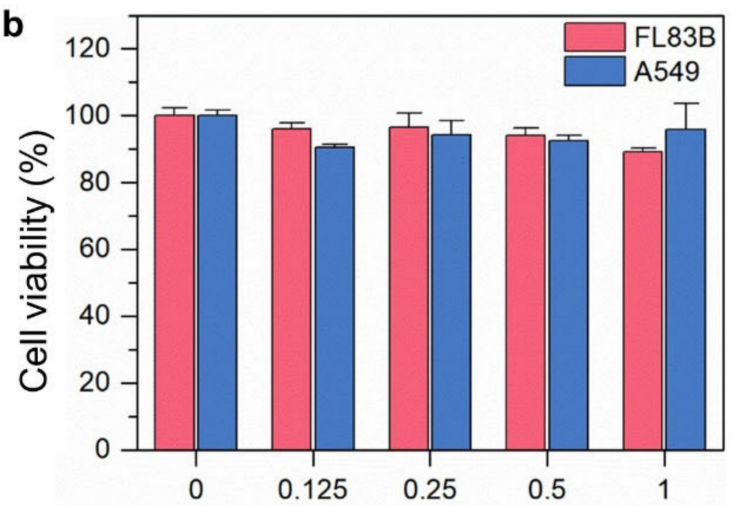

Particle concentrations $(\mathrm{mg} / \mathrm{ml})$
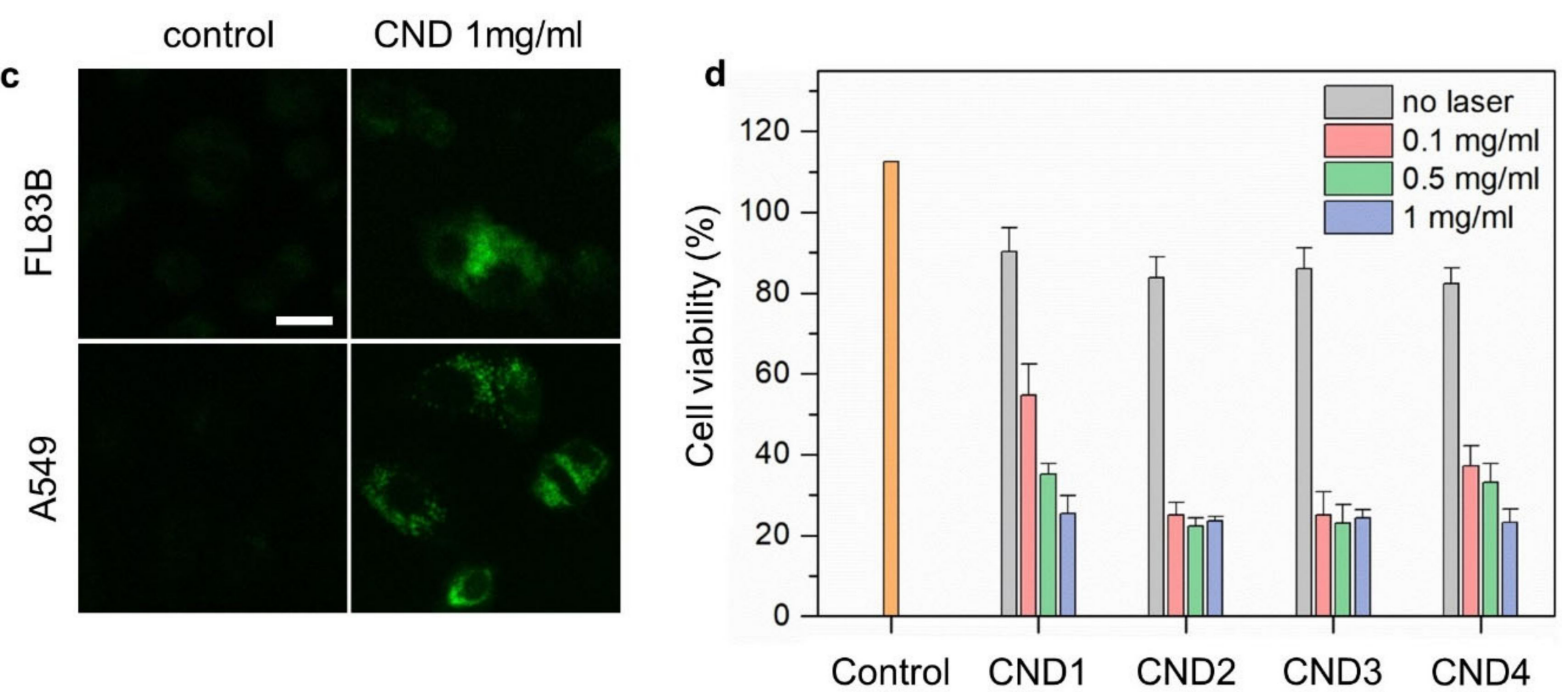

Figure 5. (a) Schematic illustration of the ROS generation by CNDs. (b) Cell viability test of the CNDs in FL83B and A549 cells using the WST-1 assay. (c) In vitro confocal microscopy images of FL83B and A549 cells with CNDs. The scale bar represents $25 \mu \mathrm{m}$. (d) Cell viabilities of A549 cells measured by the CCK-8 assay after photodynamic treatment at different concentrations of the CNDs. The error bars are obtained from three independent experiments and represent the standard deviation. 
Subsequently, we demonstrated apoptotic cell death induced by ROS generation to realize PDT based on our CNDs. Firstly, the cell viability of CNDs was investigated in normal musculus hepatocyte (FL83B) and lung epithelial carcinoma (A549) cells using the cell counting kit-8 (CCK-8) assay (Figure 5b). The cells were incubated for $1 \mathrm{~d}$ in a cell culture media containing CNDs with concentrations ranging from $0.125-1 \mathrm{mg} \cdot \mathrm{mL}^{-1}$. The cell viabilities of the CNDs fell in the range of $90-100 \%$ at concentrations below $1 \mathrm{mg} \cdot \mathrm{mL}^{-1}$ for both FL83B and A549 cells. Figure 5c shows confocal microscopy images of the FL83B and A549 cells after treatment with the CNDs to confirm their cellular internalization. The cells treated with the CNDs were green compared to the control group, which was not visualized. These results indicated that the CNDs were capable of penetrating into the cytosol through the cell membrane. Hence, CNDs can be used as a potential diagnostic and therapeutic agent.

The PDT efficacy of the CNDs at different concentrations was evaluated in vitro using A549 cells under $473 \mathrm{~nm}$ two-photon excitation. The experimental group treated with the CNDs showed a significant decrease in cell viability of $\sim 25 \%$ (Figure $5 \mathrm{~d}$ ). CND2-CND4 with surface molecular fluorophores exhibited higher PDT efficacies than those exhibited by CND1. This is consistent with previous ROS data that indicated a central role of nonradiative trap states (induced by the addition of $\mathrm{CA}$ ) in ROS generation.

\section{Conclusions}

In summary, we have successfully synthesized CNDs at relatively low temperatures $\left(<100{ }^{\circ} \mathrm{C}\right)$ using EA as the major precursor and CA as an additive. The roles of EA and CA were qualitatively analyzed by controlling their molar percentages. The carbogenic core states and the surface defective states, created primarily through the carbonization of EA, were responsible for the occurrence of $750 \mathrm{~nm}$ NIR PL and excitation-dependent visible PL, respectively. In the presence of CA, CAFMs were formed on the surface of the CNDs, resulting in the formation of molecular emissive states. These states are associated with the occurrence of excitation-independent and narrow-bandwidth emissions. Furthermore, the addition of CA resulted in the formation of incomplete chemical moieties (comprising dangling bonds and radicals), which led to the creation of non-radiative trap states. These non-radiative trap states permit the generation of ROS. Using our CNDs, we demonstrated that PDT induced apoptotic cell death in A549 cells, which might be a useful treatment for cell carcinoma. We anticipate that these new insights into the energy states of CNDs will result in significant improvements in a variety of applications, ranging from photoelectrochemical and photocatalytic applications to biological labeling, biosensing, and medical treatment.

Supplementary Materials: The following supporting information can be downloaded at: https: / /www.mdpi.com/article/10.3390/nano12010070/s1, Figure S1: TEM; Figure S2: Size distribution; Figure S3: HPLC; Figure S4: DLS; Figure S5: Zeta potentials; Figure S6: Raman spectroscopy; Figure S7: C1s XPS; Figure S8: N1s XPS; Figure S9: O1s XPS; Figure S10: XPS survey; Figure S11: UV-visible absorption spectroscopy; Figure S12: Photostability; Figure S13: PL intensity; Figure S14: SOSG PL; Table S1: Elemental analysis; Table S2: Absolute quantum yield; Table S3: PL/surface chemistry summary.

Author Contributions: Conceptualization, Y.P. and W.K.; methodology, Y.K. and S.H.; validation, Y.K.; formal analysis, Y.P.; investigation, Y.K., W.P., M.K. and K.K.; resources, J.J., S.K.H. and W.K.; data curation, Y.P. and W.K.; writing-original draft preparation, Y.K., Y.P. and S.H.; writing-review and editing, S.K.H. and W.K.; visualization, K.K.; supervision, S.K.H. and W.K.; project administration, W.K.; funding acquisition, J.J., S.K.H. and W.K. All authors have read and agreed to the published version of the manuscript. 
Funding: This work was supported by the Basic Science Research Programs (Grant No. NRF2019R1C1C1006574 and NRF-2020R1A2C3014070) and the Korea Medical Device Development Fund (Grant No. 2020M3E5D8105732) of the National Research Foundation of Korea (NRF) funded by the Ministry of Science and ICT (MIST), Korea. This work was also supported in part by the Future-leading Project Research Fund (1.200094.01) of Ulsan National Institute of Science and Technology (UNIST).

Conflicts of Interest: The authors declare no conflict of interest.

\section{References}

1. Huang, X.; Zhang, F.; Zhu, L.; Choi, K.Y.; Guo, N.; Guo, J.; Tackett, K.; Anilkumar, P.; Liu, G.; Quan, Q.; et al. Effect of Injection Routes on the Biodistribution, Clearance, and Tumor Uptake of Carbon Dots. ACS Nano 2013, 7, 5684-5693. [CrossRef]

2. Zhu, S.; Zhang, J.; Tang, S.; Qiao, C.; Wang, L.; Wang, H.; Liu, X.; Li, B.; Li, Y.; Yu, W.; et al. Surface Chemistry Routes to Modulate the Photoluminescence of Graphene Quantum Dots: From Fluorescence Mechanism to Up-Conversion Bioimaging Applications. Adv. Funct. Mater. 2012, 22, 4732-4740. [CrossRef]

3. Bhunia, S.K.; Saha, A.; Maity, A.R.; Ray, S.C.; Jana, N.R. Carbon Nanoparticle-based Fluorescent Bioimaging Probes. Sci. Rep. 2013, 3, 1473. [CrossRef] [PubMed]

4. Tong, G.; Wang, J.; Wang, R.; Guo, X.; He, L.; Qiu, F.; Wang, G.; Zhu, B.; Zhu, X.; Liu, T. Amorphous carbon dots with high two-photon fluorescence for cellular imaging passivated by hyperbranched poly(amino amine). J. Mater. Chem. B 2015, 3, 700-706. [CrossRef] [PubMed]

5. Kasouni, A.; Chatzimitakos, T.; Stalikas, C. Bioimaging Applications of Carbon Nanodots: A Review. C—J. Carbon Res. 2019, 5, 19. [CrossRef]

6. Dai, H.; Shi, Y.; Wang, Y.; Sun, Y.; Hu, J.; Ni, P.; Li, Z. A carbon dot based biosensor for melamine detection by fluorescence resonance energy transfer. Sens. Actuators B Chem. 2014, 202, 201-208. [CrossRef]

7. Chai, L.; Zhou, J.; Feng, H.; Tang, C.; Huang, Y.; Qian, Z. Functionalized Carbon Quantum Dots with Dopamine for Tyrosinase Activity Monitoring and Inhibitor Screening: In Vitro and Intracellular Investigation. ACS Appl. Mater. Interfaces 2015, 7, 23564-23574. [CrossRef] [PubMed]

8. Cho, M.-J.; Park, S.-Y. Carbon-dot-based ratiometric fluorescence glucose biosensor. Sens. Actuators B Chem. 2019, 282, 719-729. [CrossRef]

9. Das, P.; Bose, M.; Das, A.K.; Banerjee, S.; Das, N.C. One-Step Synthesis of Fluorescent Carbon Dots for Bio-Labeling Assay. Macromol. Symp. 2018, 382, 1800077. [CrossRef]

10. Pierrat, P.; Wang, R.; Kereselidze, D.; Lux, M.; Didier, P.; Kichler, A.; Pons, F.; Lebeau, L. Efficient in vitro and in vivo pulmonary delivery of nucleic acid by carbon dot-based nanocarriers. Biomaterials 2015, 51, 290-302. [CrossRef]

11. Wang, Q.; Huang, X.; Long, Y.; Wang, X.; Zhang, H.; Zhu, R.; Liang, L.; Teng, P.; Zheng, H. Hollow luminescent carbon dots for drug delivery. Carbon N. Y. 2013, 59, 192-199. [CrossRef]

12. Feng, T.; Ai, X.; An, G.; Yang, P.; Zhao, Y. Charge-Convertible Carbon Dots for Imaging-Guided Drug Delivery with Enhanced in Vivo Cancer Therapeutic Efficiency. ACS Nano 2016, 10, 4410-4420. [CrossRef] [PubMed]

13. Tang, J.; Kong, B.; Wu, H.; Xu, M.; Wang, Y.; Wang, Y.; Zhao, D.; Zheng, G. Carbon Nanodots Featuring Efficient FRET for Real-Time Monitoring of Drug Delivery and Two-Photon Imaging. Adv. Mater. 2013, 25, 6569-6574. [CrossRef]

14. Choi, Y.; Kim, S.; Choi, M.-H.; Ryoo, S.-R.; Park, J.; Min, D.-H.; Kim, B.-S. Highly Biocompatible Carbon Nanodots for Simultaneous Bioimaging and Targeted Photodynamic Therapy In Vitro and In Vivo. Adv. Funct. Mater. 2014, 24, 5781-5789. [CrossRef]

15. Das, P.; Bhattacharyya, S.K.; Banerji, P.; Das, N.C. Acoustic cavitation assisted synthesis and characterization of photoluminescent carbon quantum dots for biological applications and their future prospective. Nano-Struct. Nano-Objects 2021, 25, 100641. [CrossRef]

16. Sarkar, S.; Banerjee, D.; Ghorai, U.K.; Das, N.S.; Chattopadhyay, K.K. Size dependent photoluminescence property of hydrothermally synthesized crystalline carbon quantum dots. J. Lumin. 2016, 178, 314-323. [CrossRef]

17. Dhenadhayalan, N.; Lin, K.-C.; Suresh, R.; Ramamurthy, P. Unravelling the Multiple Emissive States in Citric-Acid-Derived Carbon Dots. J. Phys. Chem. C 2016, 120, 1252-1261. [CrossRef]

18. Li, H.; He, X.; Kang, Z.; Huang, H.; Liu, Y.; Liu, J.; Lian, S.; Tsang, C.H.A.; Yang, X.; Lee, S.-T. Water-Soluble Fluorescent Carbon Quantum Dots and Photocatalyst Design. Angew. Chem. 2010, 122, 4532-4536. [CrossRef]

19. Ding, H.; Yu, S.-B.; Wei, J.-S.; Xiong, H.-M. Full-Color Light-Emitting Carbon Dots with a Surface-State-Controlled Luminescence Mechanism. ACS Nano 2016, 10, 484-491. [CrossRef]

20. Li, M.; Zhang, S.X.-A. Reply to Comment on "Carbon Dots with Continuously Tunable Full-Color Emission and Their Application in Ratiometric pH Sensing". Chem. Mater. 2014, 26, 6084. [CrossRef]

21. Yuan, Y.H.; Liu, Z.X.; Li, R.S.; Zou, H.Y.; Lin, M.; Liu, H.; Huang, C.Z. Synthesis of nitrogen-doping carbon dots with different photoluminescence properties by controlling the surface states. Nanoscale 2016, 8, 6770-6776. [CrossRef]

22. Pan, X.; Zhang, Y.; Sun, X.; Pan, W.; Yu, G.; Zhao, Q.; Wang, J. Carbon dots originated from methyl red with molecular state and surface state controlled emissions for sensing and imaging. J. Lumin. 2018, 204, 303-311. [CrossRef] 
23. Galande, C.; Mohite, A.D.; Naumov, A.V.; Gao, W.; Ci, L.; Ajayan, A.; Gao, H.; Srivastava, A.; Weisman, R.B.; Ajayan, P.M. Quasi-Molecular Fluorescence from Graphene Oxide. Sci. Rep. 2011, 1, 85. [CrossRef] [PubMed]

24. Krysmann, M.J.; Kelarakis, A.; Dallas, P.; Giannelis, E.P. Formation Mechanism of Carbogenic Nanoparticles with Dual Photoluminescence Emission. J. Am. Chem. Soc. 2012, 134, 747-750. [CrossRef] [PubMed]

25. Chen, D.; Gao, H.; Chen, X.; Fang, G.; Yuan, S.; Yuan, Y. Excitation-Independent Dual-Color Carbon Dots: Surface-State Controlling and Solid-State Lighting. ACS Photon. 2017, 4, 2352-2358. [CrossRef]

26. Hu, T.; Wen, Z.; Wang, C.; Thomas, T.; Wang, C.; Song, Q.; Yang, M. Temperature-controlled spectral tuning of full-color carbon dots and their strongly fluorescent solid-state polymer composites for light-emitting diodes. Nanoscale Adv. 2019, 1, 1413-1420. [CrossRef]

27. Fathi, P.; Khamo, J.S.; Huang, X.; Srivastava, I.; Esch, M.B.; Zhang, K.; Pan, D. Bulk-state and single-particle imaging are central to understanding carbon dot photo-physics and elucidating the effects of precursor composition and reaction temperature. Carbon N. Y. 2019, 145, 572-585. [CrossRef]

28. Qu, D.; Zheng, M.; Zhang, L.; Zhao, H.; Xie, Z.; Jing, X.; Haddad, R.E.; Fan, H.; Sun, Z. Formation mechanism and optimization of highly luminescent N-doped graphene quantum dots. Sci. Rep. 2014, 4, 5294. [CrossRef]

29. Kwon, W.; Do, S.; Lee, J.; Hwang, S.; Kim, J.K.; Rhee, S.-W. Freestanding Luminescent Films of Nitrogen-Rich Carbon Nanodots toward Large-Scale Phosphor-Based White-Light-Emitting Devices. Chem. Mater. 2013, 25, 1893-1899. [CrossRef]

30. Dong, Y.; Pang, H.; Bin Yang, H.; Guo, C.; Shao, J.; Chi, Y.; Li, C.M.; Yu, T. Carbon-Based Dots Co-doped with Nitrogen and Sulfur for High Quantum Yield and Excitation-Independent Emission. Angew. Chem. Int. Ed. 2013, 52, 7800-7804. [CrossRef]

31. Mao, L.-H.; Tang, W.-Q.; Deng, Z.-Y.; Liu, S.-S.; Wang, C.-F.; Chen, S. Facile Access to White Fluorescent Carbon Dots toward Light-Emitting Devices. Ind. Eng. Chem. Res. 2014, 53, 6417-6425. [CrossRef]

32. Wang, F.; Kreiter, M.; He, B.; Pang, S.; Liu, C.-Y. Synthesis of direct white-light emitting carbogenic quantum dots. Chem. Commun. 2010, 46, 3309-3311. [CrossRef] [PubMed]

33. Hu, X.; Cheng, L.; Wang, N.; Sun, L.; Wang, W.; Liu, W. Surface passivated carbon nanodots prepared by microwave assisted pyrolysis: Effect of carboxyl group in precursors on fluorescence properties. RSC Adv. 2014, 4, 18818-18826. [CrossRef]

34. Song, Y.; Zhu, S.; Zhang, S.; Fu, Y.; Wang, L.; Zhao, X.; Yang, B. Investigation from chemical structure to photoluminescent mechanism: A type of carbon dots from the pyrolysis of citric acid and an amine. J. Mater. Chem. C 2015, 3, 5976-5984. [CrossRef]

35. Xiong, Y.; Schneider, J.; Ushakova, E.V.; Rogach, A.L. Influence of molecular fluorophores on the research field of chemically synthesized carbon dots. Nano Today 2018, 23, 124-139. [CrossRef]

36. Schneider, J.; Reckmeier, C.J.; Xiong, Y.; Von Seckendorff, M.; Susha, A.S.; Kasák, P.; Rogach, A.L. Molecular Fluorescence in Citric Acid-Based Carbon Dots. J. Phys. Chem. C 2017, 121, 2014-2022. [CrossRef]

37. Gu, S.; Hsieh, C.-T.; Yuan, C.-Y.; Gandomi, Y.A.; Chang, J.-K.; Fu, C.-C.; Yang, J.-W.; Juang, R.-S. Fluorescence of functionalized graphene quantum dots prepared from infrared-assisted pyrolysis of citric acid and urea. J. Lumin. 2020, 217, 116774. [CrossRef]

38. Lin, L.; Zhang, S. Creating high yield water soluble luminescent graphene quantum dots via exfoliating and disintegrating carbon nanotubes and graphite flakes. Chem. Commun. 2012, 48, 10177-10179. [CrossRef]

39. Goncalves, A.-M.B.; Malachias, A.; Mazzoni, M.S.; Lacerda, R.G.; Magalhães-Paniago, R. Metastable phase formation and structural evolution of epitaxial graphene grown on $\mathrm{SiC}(100)$ under a temperature gradient. Nanotechnology 2012, $23,175603$. [CrossRef]

40. Vevelstad, S.J.; Grimstvedt, A.; Elnan, J.; da Silva, E.F.; Svendsen, H.F. Oxidative degradation of 2-ethanolamine: The effect of oxygen concentration and temperature on product formation. Int. J. Greenh. Gas Control. 2013, 18, 88-100. [CrossRef]

41. Chen, F.; Liu, L.; Shen, Z.; Xu, G.Q.; Hor, T.S.A. Formation of hydrogenated amorphous carbon films from polymer pyrolysis. Appl. Phys. A Mater. Sci. Process. 2002, 74, 317-319. [CrossRef]

42. Cheung, W.; Patel, M.; Ma, Y.; Chen, Y.; Xie, Q.; Lockard, J.V.; Gao, Y.; He, H. $\pi$-Plasmon absorption of carbon nanotubes for the selective and sensitive detection of Fe3+ ions. Chem. Sci. 2016, 7, 5192-5199. [CrossRef]

43. Sun, Y.-P.; Zhou, B.; Lin, Y.; Wang, W.; Fernando, K.A.S.; Pathak, P.; Meziani, M.J.; Harruff, B.A.; Wang, X.; Wang, H.; et al Quantum-Sized Carbon Dots for Bright and Colorful Photoluminescence. J. Am. Chem. Soc. 2006, 128, 7756-7757. [CrossRef] [PubMed]

44. Wang, Y.; Kalytchuk, S.; Zhang, Y.; Shi, H.; Kershaw, S.V.; Rogach, A.L. Thickness-Dependent Full-Color Emission Tunability in a Flexible Carbon Dot Ionogel. J. Phys. Chem. Lett. 2014, 5, 1412-1420. [CrossRef] [PubMed]

45. Kim, H.; Park, Y.; Beack, S.; Han, S.; Jung, D.; Cha, H.J.; Kwon, W.; Hahn, S.K. Dual-Color-Emitting Carbon Nanodots for Multicolor Bioimaging and Optogenetic Control of Ion Channels. Adv. Sci. 2017, 4, 1700325. [CrossRef] [PubMed]

46. Ding, H.; Zhou, X.-X.; Wei, J.-S.; Li, X.-B.; Qin, B.-T.; Chen, X.-B.; Xiong, H.-M. Carbon dots with red/near-infrared emissions and their intrinsic merits for biomedical applications. Carbon N. Y. 2020, 167, 322-344. [CrossRef]

47. Park, Y.; Tran, M.D.; Kim, Y.; Won, S.; Kim, Y.-H.; Lee, T.-W.; Gregorkiewicz, T.; Lee, Y.H.; Kim, J.-H.; Kwon, W. Unraveling the origin of near-infrared emission in carbon dots by ultrafast spectroscopy. Carbon 2022, 188, 229-237. [CrossRef]

48. Sinclair, L.; Brown, J.; Salim, M.G.; May, D.; Guilvaiee, B.; Hawkins, A.; Cathles, L. Optimization of fluorescence and surface adsorption of citric acid/ethanolamine carbon nanoparticles for subsurface tracers. Carbon 2020, 169, 395-402. [CrossRef]

49. Wang, B.-B.; Jin, J.-C.; Xu, Z.-Q.; Jiang, Z.-W.; Li, X.; Jiang, F.-L.; Liu, Y. Single-step synthesis of highly photoluminescent carbon dots for rapid detection of $\mathrm{Hg}^{2+}$ with excellent sensitivity. J. Colloid Interface Sci. 2019, 551, 101-110. [CrossRef] 